\title{
A study of the health conditions of child workers in a small scale leather industry in Calcutta
}

\author{
Sampa Mitra
}

\begin{abstract}
Forty male children aged between seven and 14 years, working in small scale leather workshops in a slum locality in Calcutta were studied, along with a control group of 40 nonworking male children of the same age group, same locality, and the same socioeconomic class. Three specific health problems-namely, low back and ankle pain, dizziness, and tingling pain in the hands were found in a significantly higher proportion in the working children. For height, weight, nutritional state, and general morbidity pattern, however there were no significant differences between the two groups. Possibly the particular sitting posture of the child workers for long working hours and the chemical nature of the glue and solvents used in this industry were responsible for the manifestations in the working children.
\end{abstract}

\section{(British Fournal of Industrial Medicine 1993;50:938-940)}

One of the abiding forces of social injustice and exploitation is the institution of child labour for the bare need of survival. Working children are, on the one hand, deprived of school education, play, recreation, love and care at home, and the company of their parents, siblings, and friendsthey are deprived of their "childhood". Also, they are subjected to various kinds of occupational hazards. Few studies have been performed to date to assess the health conditions of working children, particularly in relation to their specific occupations and workplaces. It is with this background that, the present study was undertaken. A location in the city of Calcutta was chosen where there were many small scale leather working establishments employing child workers.

Department of Community Medicine, R G Kar Medical College, Calcutta, India

S Mitra
The main objectives of the study were: (1) to study the health state and morbidity patterns, along with the living and working conditions of the children working in these leather workshops; (2) to compare the health conditions of the working children with those of the children not at work, living in the same environment, and belonging to the same socioeconomic class; and (3) to identify any specific health risks to the children in this particular industry.

\section{Materials and methods}

In central Calcutta, numerous small workshops are located in a big slum area, devoted to making leather articles, mostly "chappals" (leather slippers). The residents are mainly Urdu speaking Muslims. The first phase of the study comprised repeated visits to that area, making contacts with the local people, particularly the shop owners, to explain what was the aim of the study. The shop owners were all residents of the slum and in most cases, also worked in the shops themselves. At first the owners totally refused to cooperate and even denied that they used child workers in their shops; they were sceptical about my identity and my real motives, and were on their guard (a "guilty conscience"). It was a big task motivating them to cooperate. This was achieved by repeated visits and personal approaches to the shop owners from door to door. Ultimately, however, they were convinced that I did not belong to any administrative or legislative organisation and the real intention of the proposed work was genuinely to study the health and wellbeing of the children of the area-not to harm their business. I consider that this was the most important and difficult part of the study and it took a considerable share of the limited time available. Elements of suspicion and hostility always persisted among the shop owners and played a major hindering factor throughout the study. In all, 40 working children in the age range seven to 14 years were studied. Under the prevailing conditions, it was the maximum number I could study in the particular area. Forty nonworking children of the same locality, in the same 
age range, and belonging to the same social group were simultaneously studied as controls.

The interview of the children was carried out on a preformed schedule. A general clinical examination with measuring tape, portable weighing machine, torch, and stethoscope was carried out for every child.

The child workers were called for interview one by one so as not to hamper the work schedule of the shop. Usually it took about $\mathbf{4 5}$ minutes to study one child. The interview usually took place in the open passage in front of the respective workshop. The shop owner or someone on his behalf was always present during the interview. This imposed some difficulty in asking questions freely, particularly about wages and treatment from the owner.

It was initially intended to make a longitudinal study to determine not only the prevalence but also the incidence of health problems among the children, but this was not possible, primarily due to frequent turnover of child workers in this industry. One shop owner discharges some of his child workers during slack periods of business, and these are recruited by some other shop owner, according to the individual owner's need and convenience.

\section{Results and discussion}

AGE DISTRIBUTION OF THE CHILD WORKERS

In general, $52.5 \%$ were in the age group seven to 10 years and $47.5 \%$ were in the older group of 11 to 14 years. The maximum number $(40 \%)$ were nine to 10 years of age.

\section{WORK ENVIRONMENT}

The work places were single room shops situated in the slum area. There were two types of rooms: the smaller type of 6-8 feet $\times 4-8$ feet $\times 6-10$ feet and the larger type of 8-10 feet $\times 6-10$ feet $\times 10-12$ feet. Many of the larger rooms had a two tier arrangement to accommodate more workers. Mostly, there were six to nine workers for each shop, and the number varied from three to 11 . Natural lighting and ventilation were poor in all the shops, as the rooms had only one door and one small window. All the shops had electric light and a ceiling fan, however.

In $25 \%$ of shops, drinking water from a nearby public tap was stored in earthen pitchers or plastic jugs. Workers in all of the shops used community latrines in the slum when needed.

\section{NATURE OF WORK}

Most of the child workers were considered as trainees, popularly nicknamed by the owners and adult colleagues as "tenia". Their usual work was to paint adhesive glue on pieces of leather supplied to them. Some also had to perform the cutting and
Table 1 Distribution of the working children by total working hours per day:

\begin{tabular}{lc}
\hline Working hours per day & No of children (\%) \\
\hline $5-7+$ & $2(5)$ \\
$8-10^{+}$ & $4(10)$ \\
$11-12+$ & $9(22 \cdot 5)$ \\
$13-14+$ & $22(55)$ \\
$15-17+$ & $3(7 \cdot 5)$ \\
\hline
\end{tabular}

sizing of leather. They also had to carry out odd jobs like bringing tea, calling someone, carrying loads of finished products to the sellers' agent etc. The common working posture of the child workers was to sit cross legged on the floor, stooping forward.

\section{WORKING HOURS}

Usually the work started at 9:00 am (varying between 8:00 and 10:00 AM) and and continued until 10:00 pm (9:00-11:00 pm). During a good business season, work continued even until midnight. Table 1 shows that $55 \%$ of the children worked for 13-14 hours a day and in all 85\% worked for more than 10 hours a day. A few children $(5 \%)$ worked on a part time basis (five to seven hours a day).

Sunday was the usual holiday and the shops closed for about two weeks during the major Islamic festivals like "Id".

\section{WAGES}

The working children were usually considered as trainee workers and accordingly their wages were much lower than those of the adult workers. Their usual wages ranged from five to 40 Rupees (60 Rupees $=£ 1$ (approximately)) a week and $15 \%$ of them received no wages at all.

Queries about the wages were difficult as the interviews in most cases were conducted in front of the shop owner or a representative. Sometimes questions about wages were answered by the employer himself. So, there is a possibility that their actual wage range could be even lower.

\section{LIVING ENVIRONMENT}

Some $95 \%$ of the study children and all of the control children lived in that particular slum so the living environments of both of the groups were identical. Universally, there was one living room for each family joined by a common passage. Average measurements of the room was $8 \mathrm{ft} \times 8 \mathrm{ft} \times 8 \mathrm{ft}$. The room had a cemented floor, brick walls, and tiled roof. All the rooms had electrical connections. There was no separate kitchen for any family and cooking was done in the living room. Drinking water had to be collected from a public tap and there were community latrines and bathrooms. 
Table 2 Health problems of the working children

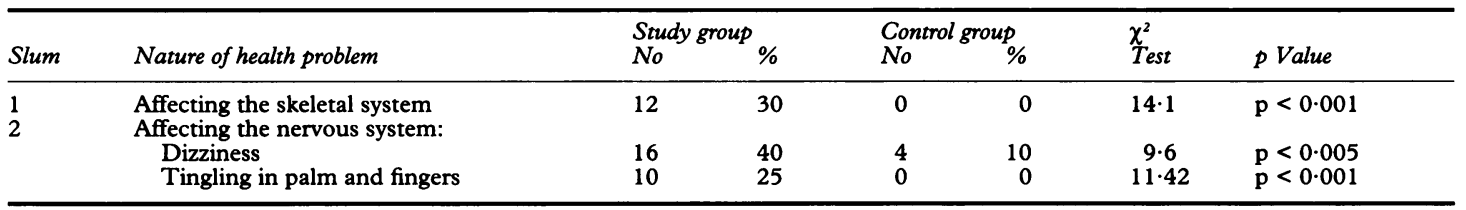

HEALTH

\section{Anthropometric measurements}

The heights and weights were recorded during the interview as useful indicators of physical growth and development. Surprisingly no significant differences were found between the mean weights of the study and control groups, although both the groups lagged much below the average high income Indian standard. ${ }^{1}$

\section{Nutritional state}

Occurrence of specific signs and symptoms of nutritional deficiency-for example Bitot's spot, night blindness, glossitis, angular stomatitis, dental caries-were found more in the working children compared with the control group, although the difference was not statistically significant.

\section{Morbidity pattern}

An attempt was made to assess the health conditions of the children and to detect any disease or ailment affecting any organ or system of the body, but no statistically significant difference was found between the two groups regarding the liver and alimentary system, respiratory system, cardiovascular system, and skin, although the overall prevalence of morbidity was of a higher order in the working children. Interestingly, a few specific health problems involving the skeletal and the nervous system were found in the working children in a proportion that was statistically significant, even within such a small sample size (table 2 ).

Symptoms and signs relating to the skeletal system like low back pain, pain in the ankles, pain and tenderness over the lower thoracic vertebrae etc were found in $30 \%$ of the working children and none of the non-working group. Among the neurological manifestations, frequent attacks of dizziness were found in $40 \%$ of the working and $10 \%$ of the non-working children. Tingling sensations in fingers and palms, occurring more in the evening, were reported by $25 \%$ of the working and none of the non-working children.

There is a probability that these particular affections of the skeletal system and of the central and peripheral nervous system found in the working children may have an aetiological relation to their participation in the particular industry. Whereas the skeletal effects may be due to their prolonged sitting in a typical posture and lack of play, the neurological affections may be causally related to their particular occupation. It has been reported that cheap glue, commonly used by the small scale shoe factories, contains some preservatives (sodium pentachlorophenate, $p$-chloro-m-cresol) that are known to be neurotoxic. ${ }^{2}$ It has been noted also that glue solvents ( $\mathrm{n}$-hexane and methyl butyl ketone) share common metabolites which are neurotoxic. ${ }^{3} \mathrm{~A}$ survey of publications on specific occupational diseases among child workers engaged in similar work elsewhere in the world produced similar findings by other investigators. ${ }^{4-6}$

I am deeply indebted to Dr B B Chatterjee, ExProfessor and Head, Department of Occupational Health, All India Institute of Hygiene and Public Health, Calcutta, for his valuable help and advice throughout this study. Gratitude is also due to Dr S P Mukhopadhyay, Professor and Head, Department of Social and Preventive Medicine, All India Institute of Hygiene and Public Health, Calcutta, for his interest in this work and his encouragement. I gratefully acknowledge Dr D P Mitra for his help, especially during the field work, that made the study feasible.

The study was undertaken when I was attached to the All India Institute of Hygiene and Public Health, Calcutta, India.

1 Indian Council of Medical Research. Nutrition Atlas of India, 2nd ed. New Delhi: ICMR, 1971.

2 Divakaran S. Handbook of glue and gelatine, Madras; Indian Leather Publishers, 1984.

3 Casarett LJ, Doull, J. Toxicology Doull J, Klaassen DC, Amdur MO, 2nd New York: Macmillan, 1980;469.

4 The evaluation of risk from radiation. International Commission on Radiological Protection, Oxford: Pergamon Press, 1966.

5 Maaroufi N. Report on the toxic effects of TOCP and other chemicals [thesis]. Rabat; 1973.

6 Albritti G, Siracusa A, Ciachetti G, et al Shoemakers' polyneuropathy in Italy: the aetiological problem, $\mathrm{Br} \mathcal{F}$ Ind Med, 33, 1976, 92-97.

Accepted 11 January 1993 